\title{
Epidemiology and burden of nasal congestion
}

This article was published in the following Dove Press journal:

International Journal of General Medicine

15 February 2010

Number of times this article has been viewed

\section{Michael Stewart ${ }^{\prime}$ \\ BJ Ferguson ${ }^{2}$ \\ Len Fromer ${ }^{3}$}

'Department of Otorhinolaryngology, Weill Cornell Medical College,

New York-Presbyterian Hospital/Weill

Cornell Medical Center, USA;

${ }^{2}$ Department of Otolaryngology,

University of Pittsburgh School

of Medicine, USA; ${ }^{3}$ University of

California, Los Angeles; David Geffen

School of Medicine Los Angeles,

California, USA
Correspondence: Michael Stewart

Department of Otorhinolaryngology,

Weill Cornell Medical College,

1305 York Avenue, 5th floor,

New York, NY 1002I, USA

$\mathrm{Tel}+\mathrm{I}(646) 962-4777$

$\mathrm{Fax}+\mathrm{I}(646) 962-0388$

Email mgs2002@med.cornell.edu
Abstract: Nasal congestion, which may be described as fullness, obstruction, reduced airflow, or being "stuffed up," is a commonly encountered symptom in clinical practice. Systematic study of congestion has largely considered it as a component of a disease state. Conditions associated with congestion include nasal polyposis, obstructive sleep apnea, and anatomic variation; however, most information on the burden of congestion comes from studies of allergic rhinitis and rhinosinusitis, diseases of which congestion is the major symptom. Congestion can be caused by other rhinologic conditions, such as non-allergic rhinitis, viral or bacterial rhinitis, and vasomotor rhinitis. Allergic rhinitis affects as much as one quarter of the population worldwide and imposes a significant economic burden. Additionally, allergic rhinitis significantly impairs quality of life; congestion causes allergic rhinitis sufferers decreased daytime productivity at work or school and reduces night-time sleep time and quality. Annually, rhinosinusitis affects tens of millions of Americans and leads to approximately $\$ 6$ billion in overall health care expenditures; it has been found to be one of the most costly physical conditions for US employers. Given the high prevalence and significant social and economic burden of nasal congestion, this symptom should be a key consideration in treating patients with rhinologic disease, and there continues to be a significant unmet medical need for effective treatment options for this condition.

Keywords: allergic rhinitis, congestion, epidemiology, obstruction, rhinosinusitis

\section{Introduction}

Congestion is a commonly encountered symptom in clinical practice, although significant variability exists in how patients and physicians define the term. Congestion can be described as fullness, blockage, or obstruction of the nasal cavity, which prevents airflow. Obstruction can be synonymous with congestion, but obstruction usually refers to irreversible blockage. For this review, we are referring to reversible congestion, which should not be confused with obstruction. Often, patients simply complain of being "stopped up" or "stuffed up" or having to breathe through the mouth. When a patient reports congestion, the clinician should use a detailed medical history, patientreported symptoms, and physical findings to help discern the underlying etiology, which may be a fixed anatomical cause or reversible and spontaneously resolving causes, such as nasal allergy or an upper respiratory infection. Although the physician should attempt to determine if the symptom can be more objectively defined and assessed, the sensation of congestion is a subjective symptom, and the patient's perception of congestion may not correlate with physical findings. In fact, the correlation between objective obstruction and airflow, and the subjective sensation of obstruction is poor, ${ }^{1}$ but reversible congestion and asymmetry can improve the correlation. 
Reversible nasal congestion is usually caused by mucosal inflammation and secretions. In contrast, fixed or relatively constant congestion (ie, obstruction) may be due to occlusion (eg, nasal polyps, foreign body), anatomical variation (eg, septal deformity, turbinate hypertrophy) or, rarely, neoplasm. In some cases, abnormal sensory perception may also contribute to a patient's perception of nasal congestion. A differential diagnosis of reversible nasal congestion includes allergic rhinitis, nonallergic rhinitis, vasomotor rhinitis, exaggerated nasal cycle, acute viral rhinitis, acute viral rhinosinusitis, acute bacterial rhinitis, acute bacterial rhinosinusitis, chronic inflammatory or infectious rhinosinusitis, rhinitis medicamentosa, sarcoidosis, Wegener's granulomatosis, Churg-Strauss syndrome, and rhinoscleroma. This review primarily addresses congestion caused by nasal mucosal inflammation, which may be either acute or chronic, and is the primary pathophysiologic mechanism underlying congestion in the common upper respiratory disorders.

\section{Epidemiology of nasal congestion and associated diseases}

Nasal congestion has not been extensively studied in the general population, and most studies of congestion have been conducted in patients with diagnosed rhinologic disease. Allergic rhinitis accounts for a large proportion of all rhinitis cases and is a common cause of nasal congestion. ${ }^{2,3}$ Over the past 2 to 3 decades, the prevalence of allergic rhinitis has been increasing worldwide. ${ }^{4,5}$ Estimates of allergic rhinitis prevalence vary, ranging from as low as $10 \%$ to as high as $40 \%,{ }^{4}$ with the disparity likely due to nonstandardized diagnostic criteria and differences in methodology and patient population in epidemiologic studies. ${ }^{5}$ Nonetheless, it is generally accepted that approximately $10 \%$ to $20 \%$ of the global population suffers from allergic rhinitis - an increase from reported prevalence rates in previous decades. ${ }^{4}$ Part of the reported increase in prevalence may be due to increased awareness and interest in allergy treatments, and greater physician and public awareness of allergic rhinitis. ${ }^{4}$ However, the true prevalence of allergic rhinitis may actually be underestimated, as epidemiologic research relies heavily on physician diagnosis. Thus, studies may not capture patients who have undiagnosed allergic rhinitis or those who self-medicate.

In the United States, the estimated prevalence of allergic rhinitis ranges from $9 \%$ to $16 \% .{ }^{6}$ Allergic rhinitis is the most common atopic condition in the United States ${ }^{7}$ and is one of the most prevalent chronic conditions in pediatric and adolescent populations, with greater than $80 \%$ of patients suffering from allergic rhinitis developing symptoms before the age of 20 years. ${ }^{2-4}$ Unfortunately, allergic rhinitis becomes a chronic condition for most sufferers, as symptom resolution occurs in only $10 \%$ to $20 \%$ of children within 10 years of diagnosis. ${ }^{5}$ In a 2003 telephone survey of 1011 adults conducted by the Gallup organization, $50 \%$ of the US population reported suffering from allergies, which equated with a $10 \%$ increase from $1999 .{ }^{8}$ In this survey, nose and throat symptoms, including sneezing, congestion, and rhinorrhea, were reported by $98 \%$ of allergy sufferers, while $75 \%$ and $55 \%$ reported itchy eyes and watery eyes, respectively. Sixty percent of allergy sufferers perceived the symptoms as severe enough to use either over-the-counter $(75 \%)$ or prescription medications (48\%). Of the prescription drug users who sought medical attention, treatment was directed at nasal symptoms in $67 \%$ of patients and ocular symptoms in $55 \%$ of this population. ${ }^{8}$ Another comprehensive survey interviewed 61,655 adults across the United States and found that 1 in 7 adults aged 18 years or older, or $14 \%$, had been diagnosed with nasal allergies. ${ }^{9}$ This survey also found that nasal congestion was the most frequently reported symptom, with $60 \%$ of those interviewed reporting a "stuffed-up nose" either every day (40\%) or on most days (20\%) during the month in which symptoms were at their worst. ${ }^{9}$

Additional studies have confirmed that allergic rhinitis and corresponding congestion are problematic worldwide. In a cross-sectional, population-based survey of 9646 European adults, $40 \%$ of subjects reported a previous diagnosis or symptoms consistent with allergic rhinitis and were referred for clinical examination by an investigator. ${ }^{10}$ The prevalence of clinically confirmable allergic rhinitis in the general population in this survey ranged from $17 \%$ in Italy to $29 \%$ in Belgium, with an overall estimated prevalence of $23 \%$ for all surveyed countries (Table 1). ${ }^{10}$ As in the United States, allergic rhinitis sufferers in Europe frequently report nasal

Table I Prevalence of clinically confirmable allergic rhinitis in Europe

\begin{tabular}{ll}
\hline Country & $\begin{array}{l}\text { Prevalence, } \\
\%(95 \% \text { confidence interval) }\end{array}$ \\
\hline Belgium & $28.5(24.5-32.5)$ \\
France & $24.5(21.0-28.0)$ \\
Germany & $20.6(16.5-24.6)$ \\
Italy & $16.9(12.9-20.9)$ \\
Spain & $21.5(18.5-24.4)$ \\
United Kingdom & $26.0(20.3-31.7)$ \\
All countries & $22.7(21.1-24.2)$ \\
\hline
\end{tabular}

Reprinted with permission from BauchauV, Durham SR. Prevalence and rate of diagnosis of allergic rhinitis in Europe. Eur Respir J. 2004;24(5):758-764. ${ }^{10}$ Copright (C 2004 European Respiratory Society Journals Ltd. 
congestion as a problematic disease symptom; in this same European survey, nasal congestion was reported by $59 \%$ of patients with a clinical diagnosis of allergic rhinitis. ${ }^{10}$ Similarly, in a survey of 562 allergic rhinitis sufferers in Belgium, physician-diagnosed nasal congestion was reported in 53\% of patients seeking medical attention for their condition. ${ }^{11}$ The apparent increase in the prevalence of allergic rhinitis in studies worldwide highlights the need for more effective treatment options for allergic rhinitis in general, and the more troublesome symptoms of this disease, such as congestion, in particular.

Nasal congestion is not limited to allergic rhinitis; it is a common and troublesome symptom of other conditions affecting the sinonasal passages, such as rhinosinusitis. ${ }^{12,13}$ Rhinosinusitis is defined as inflammation of the paranasal sinuses and contiguous nasal mucosa and can be classified as either acute, with symptom duration of less than 4 weeks, or chronic, where symptoms persist for 12 weeks or longer. In addition to nasal congestion, the symptoms of rhinosinusitis can include headache, facial pain, maxillary toothache, impaired sense of smell, and rhinorrhea. ${ }^{14}$ Rhinosinusitis is one of the most common diagnoses encountered in clinical practice, ${ }^{15}$ affecting 1 in 6 adults in the United States. ${ }^{14}$ These statistics likely underestimate the true incidence of rhinosinusitis in the United States, as an estimated 20\% of people affected by this condition may not seek medical attention. ${ }^{14}$ Rhinosinusitis is also an international issue: in a large, multicountry survey of physicians and patients, physician-diagnosed rhinosinusitis was reported by over $10 \%$ of the surveyed populations in Europe, Japan, and the United States in 2001. ${ }^{16}$ The incidence of congestion is highlighted by 2 recent studies from France. In the first study of 4611 patients with rhinosinusitis, nasal obstruction was observed in $66 \%$ of patients. ${ }^{13}$ In the other study, nasal obstruction was observed in $70 \%$ of 755 patients. ${ }^{12}$

In addition to allergic rhinitis and rhinosinusitis, severe nasal congestion is a primary symptom of nasal polyposis. ${ }^{17,18}$ Nasal polyposis is usually a bilateral disease, and polyps primarily occur in the middle meatus and originate from the nasal mucous membrane of the outlets (ostia, clefts, recesses) from the paranasal sinuses. Nasal polyps are edematous sacs of scant cellular element, covered by pseudostratified respiratory epithelium. Nasal polyp formation is often caused by chronic inflammatory rhinosinusitis. Nasal blockage from polyps is caused by physical obstruction and occasionally a ball valve effect, in which the nasal polyp swings backward or forward, allowing or preventing airflow. ${ }^{18}$ In a study of 109 Spanish nasal polyposis patients, nasal obstruction and loss of smell were most commonly identified by those patients as their most severe symptoms. ${ }^{17}$ The prevalence of nasal polyposis is currently estimated at $2 \%$ to $4 \%$ of the population; the prevalence increases with age and is higher in patients with aspirin intolerance, asthma, chronic sinusitis, and cystic fibrosis. ${ }^{18}$

\section{Burden of nasal congestion}

The economic impact of nasal congestion, in isolation, and its unique burden on quality of life (QOL) are unstudied. However, data are available on the impact of allergic rhinitis and rhinosinusitis, diseases in which congestion is the major symptom.

\section{Economic and quality-of-life burden of allergic rhinitis}

The effects of allergic rhinitis on individual patients as well as society as a whole are extensive, resulting in significant direct and indirect costs as well as diminished QOL. In the United States, the estimated total cost of treating the primary diagnosis of allergic rhinitis was $\$ 1.9$ billion in 1996, and costs increased to $\$ 4$ billion when allergic rhinitis as a secondary diagnosis was included. ${ }^{19}$ Allergic rhinitis accounted for approximately 12 million office visits to health care providers in $2006^{20}$ and nasal congestion accounted for more than 13 million office visits in $2005 .{ }^{21}$ A 1996 analysis found that outpatient expenses for allergic rhinitis totaled $\$ 3.7$ billion in the United States, while the expense of both prescription and over-the-counter medications was estimated at $\$ 1.5$ billion. ${ }^{19}$ Additionally, allergic rhinitis produces indirect costs by reducing work productivity and academic performance. Symptoms, such as nasal congestion, cause high rates of absenteeism as well as "presenteeism," where employees are present but underperforming. Allergic rhinitis is estimated to be responsible for 3.8 million missed days from work and school in the United States, ${ }^{22}$ as well as 4.23 million days of reduced functioning. ${ }^{23}$

Conditions comorbid with allergic rhinitis also place an economic strain on society. For example, allergic rhinitis has been documented in up to $67 \%$ of patients with chronic rhinosinusitis, and expenditures for rhinosinusitis totaled $\$ 3.5$ billion in $1996 .{ }^{19}$ Similarly, asthma, which affects $\geq 14$ million Americans annually, ${ }^{24}$ is frequently comorbid with allergic rhinitis, as these 2 diseases are perceived as a continuum of airway disease. ${ }^{25}$ In fact, allergic rhinitis has been reported in $86 \%$ of patients with asthma, while asthma was documented in $21 \%$ of allergy sufferers. ${ }^{5}$ In 1998 in the United States, the direct and indirect costs of 
asthma were estimated at over $\$ 12.7$ billion annually, ${ }^{24}$ and estimates by the Task Force on Allergic Disorders indicate that annual direct costs alone would reach $\$ 14.5$ billion in the year $2000 .^{22}$

In addition to the economic expense, allergic rhinitis negatively impacts a patient's QOL. In a cross-sectional study of 111 patients with moderate-to-severe perennial allergic rhinitis and 116 healthy subjects, allergic rhinitis sufferers reported significantly lower scores on 8 of the 9 QOL dimensions from the 36-Item Short-Form Health Survey (SF-36), which is a validated global health status questionnaire (Table 2). ${ }^{26}$ Patients with perennial allergic

Table 2 Mean 36-Item short-form health survey quality-of-life scores in healthy subjects versus patients with allergic rhinitis

\begin{tabular}{|c|c|c|c|}
\hline Dimension & Mean & $\begin{array}{l}\text { Standard } \\
\text { deviation }\end{array}$ & $P$ value $^{a}$ \\
\hline \multicolumn{4}{|c|}{ Physical functioning } \\
\hline Healthy & 95.88 & 6.21 & $<0.0001$ \\
\hline Patient & 88.56 & 13.62 & \\
\hline \multicolumn{4}{|c|}{ Energy/fatigue } \\
\hline Healthy & 71.94 & 14.65 & $<0.0001$ \\
\hline Patient & 54.55 & 24.38 & \\
\hline \multicolumn{4}{|c|}{ General health perception } \\
\hline Healthy & 81.72 & 11.86 & $<0.0001$ \\
\hline Patient & 62.41 & 20.55 & \\
\hline \multicolumn{4}{|c|}{ Social functioning } \\
\hline Healthy & 91.30 & 13.26 & $<0.0001$ \\
\hline Patient & 73.09 & 23.61 & \\
\hline \multicolumn{4}{|c|}{ Role limitations - physical } \\
\hline Healthy & 92.03 & 17.63 & $<0.000$ I \\
\hline Patient & 60.59 & 37.77 & \\
\hline \multicolumn{4}{|c|}{ Role limitations - emotional } \\
\hline Healthy & 86.67 & 22.86 & $<0.0001$ \\
\hline Patient & 64.24 & 38.77 & \\
\hline \multicolumn{4}{|c|}{ Mental health } \\
\hline Healthy & 73.41 & 16.15 & 0.0005 \\
\hline Patient & 64.79 & 20.38 & \\
\hline \multicolumn{4}{|l|}{ Pain } \\
\hline Healthy & 90.32 & 16.67 & $<0.0001$ \\
\hline Patient & 76.90 & 26.04 & \\
\hline \multicolumn{4}{|c|}{ Change in health } \\
\hline Healthy & 54.09 & 13.97 & 0.177 \\
\hline Patient & 49.77 & 19.51 & \\
\hline
\end{tabular}

${ }^{a} P$ value determined by the Mann-Whitney test.

Reprinted from J Allergy Clin Immunol, Vol 94, Bousquet J, Bullinger M, Fayol C, Marquis P, Valentin B, Burtin B, Assessment of quality of life in patients with perennial allergic rhinitis with the French version of the SF-36 Health Status Questionnaire, Pages 182-188. ${ }^{26}$ Copyright (C) 1994, with permission from Mosby-Year Book, Inc. rhinitis experienced the greatest impairment of QOL in the areas of physical role limitations, pain, social functioning, general health perception, energy/fatigue, and physical functioning. ${ }^{26}$ These results, which highlight the negative burden of allergic rhinitis on QOL, have been confirmed in other studies. ${ }^{27,28}$ Meltzer et al assessed QOL in 312 people with allergic rhinitis symptomatology using the SF-36 and the disease-specific Rhinoconjunctivitis Quality of Life Questionnaire (RQLQ). ${ }^{27}$ These investigators noted statistically significant reductions in QOL measures related to physical, mental, and social functioning, including disrupted sleep pattern, fatigue, and poor concentration.

To better understand and appreciate the burden of allergy on the American population, a comprehensive national survey named "Allergies in America" was conducted in January $2006 .{ }^{9}$ To identify an adequate probability sample of adult (aged 18 years or older) allergy sufferers, 31,470 households containing 61,655 adults were surveyed by telephone, identifying 8735 adults (14.2\%) who reported being diagnosed with either seasonal (43\%) or perennial (56\%) allergies; $1 \%$ were unsure. Of those adults reporting allergies, 3482 were further screened, and 2500 were interviewed and included in the survey sample. In addition to the patient survey, 400 health care providers, including adult primary care physicians $(n=100)$, allergists $(n=100)$, otolaryngologists $(n=100)$, nurse practitioners $(n=50)$, and physician assistants $(n=50)$, participated in a telephone interview.

Survey participants reported a "stuffed-up nose" to be the most bothersome symptom of nasal allergies, and nearly $80 \%$ of respondents listed a stuffed-up nose as "extremely" or "moderately" bothersome during a nasal allergy attack. ${ }^{9}$ In comparing the survey responses of allergy sufferers and health care providers, a significant difference in opinion was noted regarding the perception of efficacy of available treatment options for allergic rhinitis. In the interview, 58\% of otolaryngologists versus $22 \%$ of patients indicated that frequent nasal allergy symptoms could be prevented in most cases. ${ }^{9}$ Similarly, $15 \%$ of allergy sufferers claimed that no truly effective treatments for nasal allergies exist, while only $1 \%$ of general practitioners and $2 \%$ of otolaryngologists believed this to be the case. ${ }^{9}$ Thus, based on this recent survey, allergic rhinitis and its associated nasal congestion remain prevalent and highly problematic across the United States, and many allergy sufferers perceive that they are not receiving adequate symptom relief with currently available therapies, in contrast to health care professionals who generally feel that effective treatments are currently available. ${ }^{9}$ 


\section{Economic and quality-of-life burden of rhinosinusitis}

Similar to allergic rhinitis, rhinosinusitis poses a significant socioeconomic burden at a national and international level. A 1996 assessment of the economic burden of rhinosinusitis noted that $\geq 45$ million people in the United States are affected annually by this condition, with an economic burden of approximately $\$ 3.5$ billion in overall health care expenditures. ${ }^{19}$ Hospitalization for sinus-related surgeries contributed to only $6 \%$ of the overall costs, while $90 \%$ of all expenditures were related to ambulatory and emergency department services. ${ }^{19}$ More recently, the annual economic burden of rhinosinusitis has been estimated at $\$ 6$ billion. ${ }^{14}$ In addition, the burden of rhinosinusitis seems to be rising in the United States. Patients suffering from rhinosinusitis reported 73 million restricted activity days between 1990 and 1992, which represented a 50\% increase compared with the restricted activity days reported between 1986 and $1988 . .^{29}$ An analysis of a multiemployer database found rhinosinusitis to be very costly to employers. ${ }^{30}$ Data on 374,799 employees from 6 large employers were analyzed and sinusitis was identified as one of the top 10 most costly physical conditions (Figure 1). ${ }^{30}$ Although the majority of these costs were medical expenditures, $41 \%$ of sinusitis-related costs were attributed to indirect costs, including work absence and disability. ${ }^{30}$
In addition, an estimated $8.4 \%$ of the Dutch population reported at least one episode of acute rhinosinusitis in 1999, ${ }^{31}$ with incidence of visits to general practitioners being 20 per 1000 for men and 33.8 per 1000 for women. ${ }^{31}$

\section{Burden of nasal congestion}

The burden of the symptom of nasal congestion has been studied in surveys of patients with allergic rhinitis. The Roper Public Affairs Group of NOP World conducted a large Internet survey between May and June 2004 that included 2355 adults and children with self-reported allergic rhinitis; caregivers of the pediatric patients answered the survey questions. ${ }^{32,33}$ Of the 2355 participants, 2002 (85\%) reported nasal congestion as a symptom of their disease and were considered eligible for further participation in the survey. ${ }^{32}$ The survey found that $40 \%$ of participants identified their congestion as severe (a score of 9 or 10 on a 10-point scale), while $36 \%$ and $25 \%$ characterized their congestion as moderate and mild, respectively. ${ }^{32}$ Compared with other symptoms of allergic rhinitis, such as itchy eyes and runny nose, allergy sufferers perceived congestion to be highly problematic: $48 \%$ of surveyed adults and $58 \%$ of caregivers identified congestion as the most bothersome symptom. ${ }^{32}$ In contrast, only $18 \%$ of adults and $20 \%$ of children chose runny nose as the most bothersome (Figure 2). ${ }^{32}$ Fifty percent of adults and $63 \%$ of caregivers also indicated that congestion was the allergy

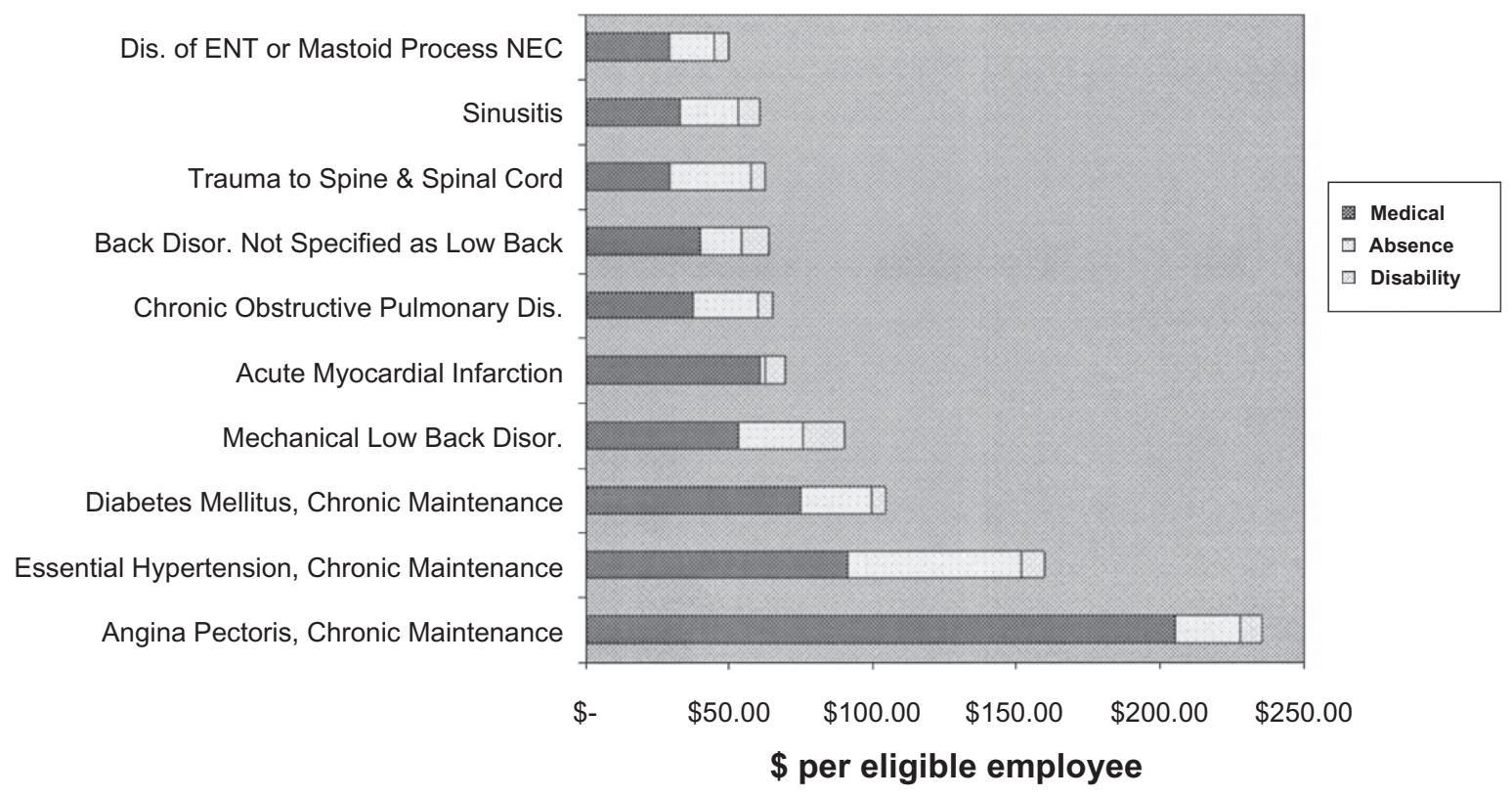

Figure I Top 10 most costly diseases to US employers in 1999. Reprinted with permission from Goetzel RZ, Hawkins K, Ozminkowski RJ,Wang S.The health and productivity cost burden of the "top 10" physical and mental health conditions affecting six large US employers in 1999.J Occup Environ Med. 2003;45(I):5-I4. ${ }^{30}$ Copyright @ 2003 Wolters Kluwer Health.

Abbreviation: NEC, not elsewhere classified. 


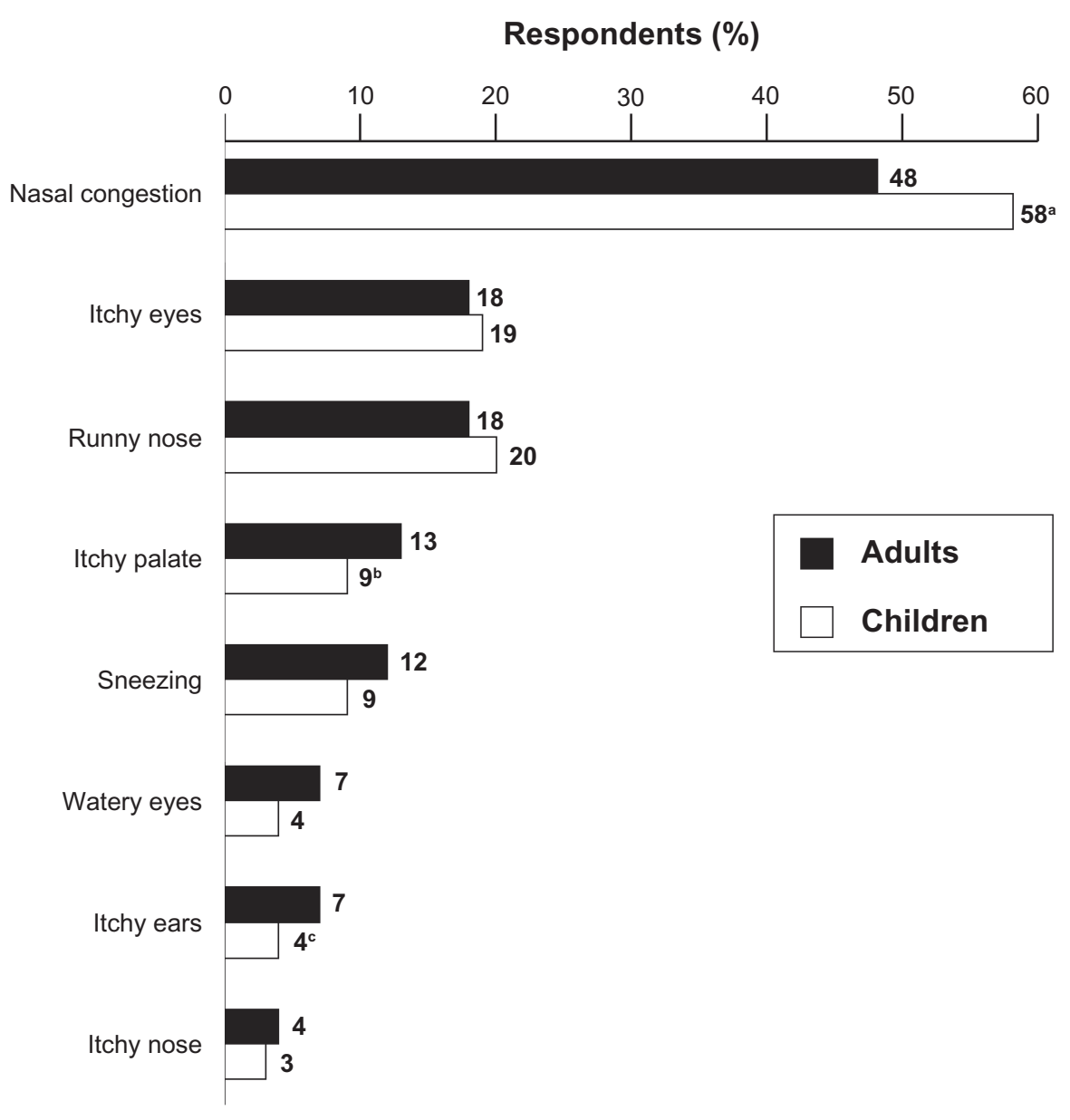

Figure 2 Most bothersome symptoms of nasal allergies. ${ }^{a} \mathrm{P}<0.05$ vs adults; ${ }^{\mathrm{b}}$ Small base population $(\mathrm{n}=69)$; ‘ Small base population ( $\mathrm{n}=68$ ).

Reprinted with permission from Shedden A. Impact of nasal congestion on quality of life and work productivity in allergic rhinitis: findings from a large online survey. Treat Respir Med. 2005;4(6):439-446. ${ }^{32}$ Copyright (C) 2005 Wolters Kluwer Health.

symptom they most wanted to prevent, compared with $\leq 19 \%$ of participants who listed runny nose (Figure 3). ${ }^{32}$ Given those results, it makes sense that $54 \%$ of adults and $69 \%$ of caregivers identified congestion as the symptom most likely to trigger a physician visit. ${ }^{32}$ Other studies have confirmed congestion to be a highly prevalent and bothersome symptom of allergic rhinitis. ${ }^{9,25}$ The continued desire by patients for congestion relief highlights once again the need for more effective therapies for this symptom.

The negative effects of nasal congestion are far reaching and impact a person's physical as well as emotional functioning. In the Roper Internet survey of allergic rhinitis sufferers, $59 \%$ of employed adults stated that nasal congestion impaired their functioning at work: poor productivity and inability to concentrate. ${ }^{32}$ Similarly, $61 \%$ of the pediatric caregivers blamed nasal congestion for their children's poor concentration and diminished performance at school. Most participants perceived that congestion interfered with their participation in daily activities, and many indicated that congestion had an adverse emotional impact, made them uncomfortable and slower in the morning, and triggered feelings of frustration. ${ }^{32}$

In addition to daytime functioning, nasal congestion adversely impacts allergic rhinitis sufferers at night. Chronic nasal congestion can cause sleep-disordered breathing and sleep fragmentation, reducing sleep time and quality as well as promoting daytime sleepiness and fatigue. ${ }^{34}$ Patients with allergic rhinitis and obstructive sleep apnea often complain of sleep-related problems. ${ }^{34}$ In the Roper Internet survey, $>80 \%$ of respondents claimed that nasal congestion was problematic during the night. ${ }^{32}$ Fifty-one percent of adult sufferers and $49 \%$ of caregivers indicated that congestion caused nighttime awakenings, and $48 \%$ of adults and $49 \%$ of caregivers claimed that congestion made falling asleep difficult (Figure 4). ${ }^{32}$ Another Internet survey, conducted by the Forbes Consulting Group in September 2005, 


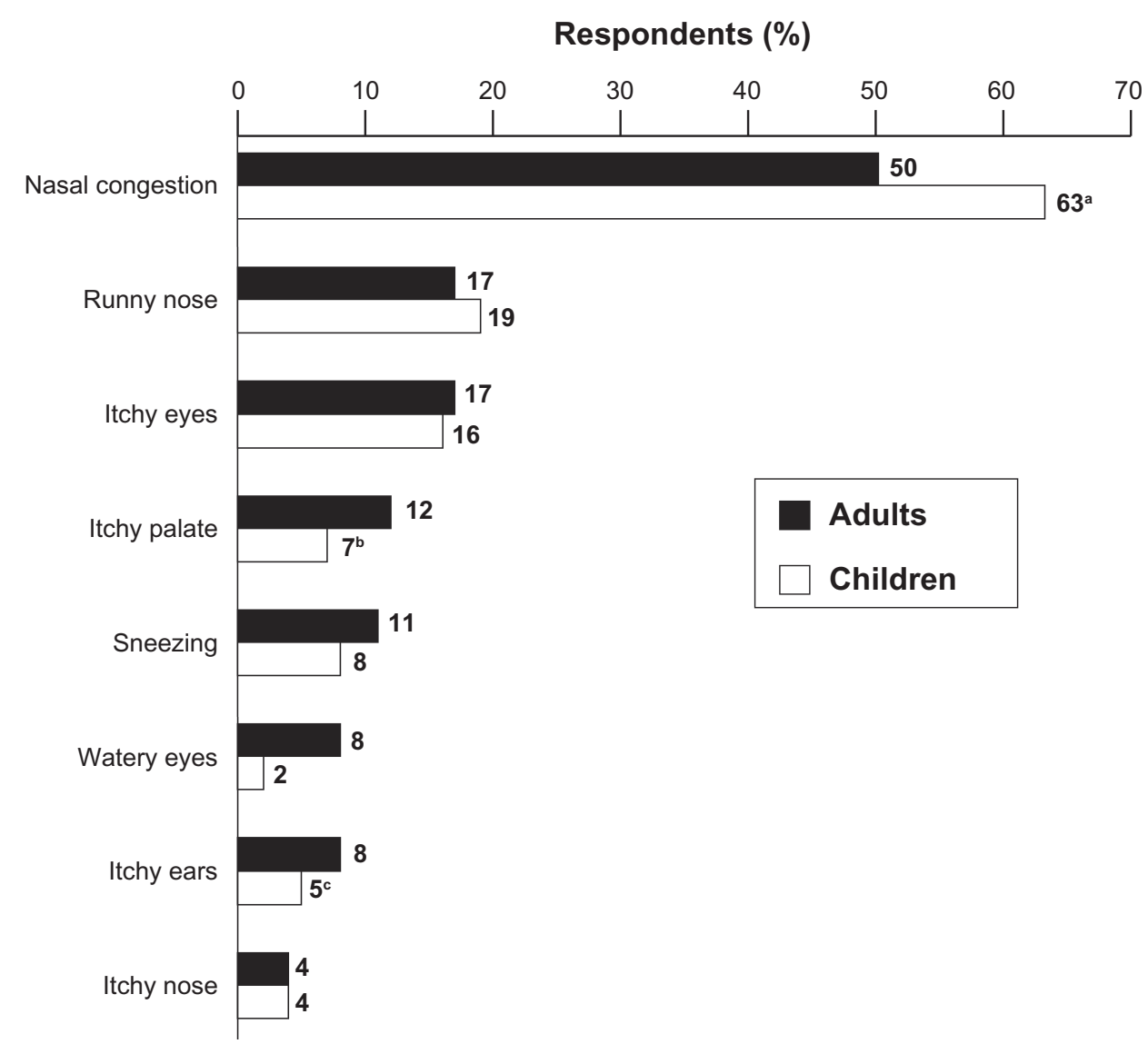

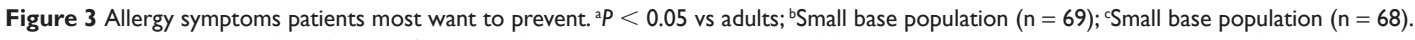
Reprinted with permission from Shedden A. Impact of nasal congestion on quality of life and work productivity in allergic rhinitis: findings from a large online survey. Treat Respir Med. 2005;4(6):439-446. ${ }^{32}$ Copyright (C) 2005 Wolters Kluwer Health.

evaluated 599 US residents with allergic rhinitis and also found that nasal congestion greatly interfered with sleep, causing daytime problems as well. ${ }^{35}$

\section{Summary}

Congestion is caused by a variety of environmental and medical conditions, and it is often perceived and described differently by patients. Congestion may be best described as a perception of reduced airflow or a sense of nasal fullness, and the patient's perception of congestion is the key consideration in clinical practice. One of the most common diseases associated with congestion is allergic rhinitis, which is estimated to affect as much as one quarter of the world's population. Patients diagnosed with this atopic disease identify congestion as the most common and typically the most troublesome symptom of allergic rhinitis, as congestion is noted in the majority of allergy sufferers. In addition, other upper respiratory conditions, including rhinosinusitis and nasal polyposis, create congestion, making congestion a highly prevalent problem.
Although the economic burden of congestion has not been extensively studied, the costs incurred by diseases associated with congestion are known to be substantial, and congestion is the most prevalent and bothersome symptom of these diseases. Studies have shown that allergic rhinitis and its associated symptoms, in addition to being an economic burden, negatively impact QOL. Congestion also has negative impacts on daytime functioning and sleep. Clearly, there is a need for more effective treatments, because patients continue to suffer from congestion, and it continues to negatively impact the quality of their lives. Taking into account the high prevalence, as well as the significant social and economic burden of nasal congestion, this symptom should be a key consideration in the treatment of patients with rhinologic disease.

\section{Acknowledgments}

Editorial assistance was provided by Henry Hamilton, $\mathrm{PhD}$, former employee of Health Science Communications, Inc., and Joyce O'Connor, MS, of Health Science Communications, Inc. This assistance was funded by Schering-Plough 


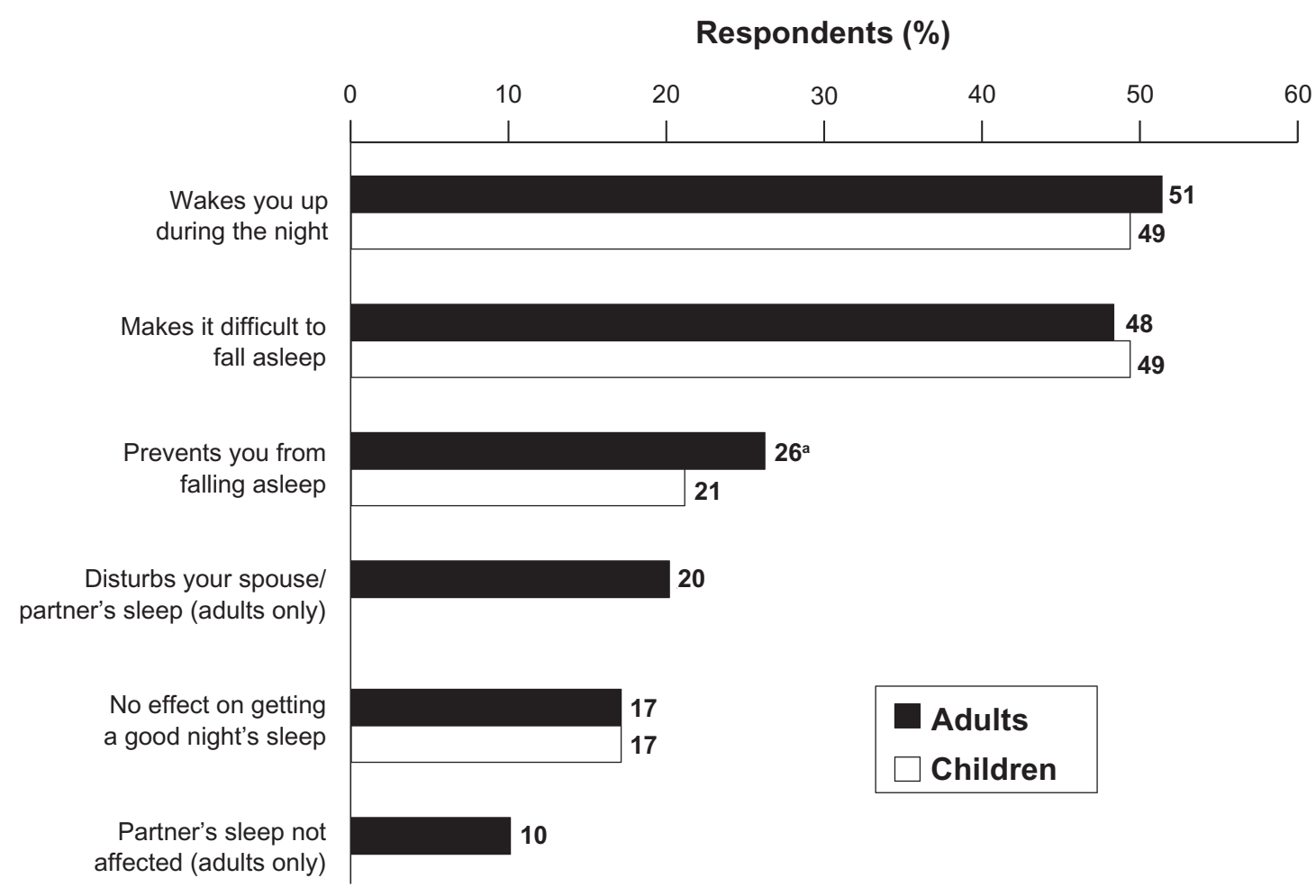

Figure 4 Impact of nasal congestion on sleep. ${ }^{a} P<0.05$ vs children.

Reprinted with permission from Shedden A. Impact of nasal congestion on quality of life and work productivity in allergic rhinitis: findings from a large online survey. Treat Respir Med. 2005;4(6):439-446. ${ }^{32}$ Copyright (C 2005 Wolters Kluwer Health.

Corporation, now Merck \& Co., Whitehouse Station, NJ, USA.

\section{Disclosures}

Dr Stewart: Medical Advisory Board, Schering-Plough Corporation, now Merck \& Co., Whitehouse Station, NJ, USA.

Dr Ferguson: Medical Advisory Board for GlaxoSmith Kline and Schering-Plough Corporation, now Merck \& Co., Whitehouse Station, NJ, USA; Research Consultant for Inverness Medtronics; Speaker's Bureau for Merck; consultant for sanofi-aventis.

Dr Fromer: none.

\section{References}

1. Stewart MG, Smith TL. Objective versus subjective outcomes assessment in rhinology. Am J Rhinol. 2005;19(5):529-535.

2. Bush RK. Etiopathogenesis and management of perennial allergic rhinitis: a state-of-the-art review. Treat Respir Med. 2004;3(1):45-57.

3. Skoner DP. Allergic rhinitis: definition, epidemiology, pathophysiology, detection, and diagnosis. J Allergy Clin Immunol. 2001;108(1 Suppl): S2-S8.

4. Lundbäck B. Epidemiology of rhinitis and asthma. Clin Exp Allergy. 1998;28 (Suppl 2):3-10.

5. Schoenwetter WF. Allergic rhinitis: epidemiology and natural history. Allergy Asthma Proc. 2000;21(1):1-6.
6. Blackwell DL, Collins JG, Coles R. Summary health statistics for U.S. adults: National Health Interview Survey, 1997. Vital Health Stat 10. 2002;(205):1-109.

7. Nathan RA, Meltzer EO, Selner JC, Storms W. Prevalence of allergic rhinitis in the United States. J Allergy Clin Immunol. 1997;99(6 Pt 2): S808-S814.

8. The 2003-2004 Gallup Study of Allergies-Phase I Report. Princeton, NJ: Multisponsor Surveys, Inc; 2004.

9. Allergies in America: Executive Summary. Available from: http://www. myallergiesinamerica.com. Accessed August 6, 2009.

10. Bauchau V, Durham SR. Prevalence and rate of diagnosis of allergic rhinitis in Europe. Eur Respir J. 2004;24(5):758-764.

11. Bachert C, van Cauwenberge P, Olbrecht J, van Schoor J. Prevalence, classification and perception of allergic and nonallergic rhinitis in Belgium. Allergy. 2006;61(6):693-698.

12. Ferrand PA, Mercier CH, Jankowski R, et al. Acute sinusitus in adults. Management by general practitioners. Presse Med. 2001;30(21): 1049-1054.

13. Pessey JJ, Reitz C, Los F. Acute rhinosinusitis in the adult: national survey of general practice management. Rev Laryngol Otol Rhinol (Bord). 2000;121(4):237-241.

14. Leggett JE. Acute sinusitis. When - and when not - to prescribe antibiotics. Postgrad Med. 2004;115(1):13-19.

15. Hickner JM, Bartlett JG, Besser RE, Gonzales R, Hoffman JR, Sande MA. Principles of appropriate antibiotic use for acute rhinosinusitis in adults: background. Ann Intern Med. 2001;

134(6):498-505

16. Datamonitor. Sinusitis: unmet need and opportunity. Available from: http://www.datamonitor.com. 2001. Accessed August 6, 2009.

17. Alobid I, Benítez P, Bernal-Sprekelsen M, et al. Nasal polyposis and its impact on quality of life: comparison between the effects of medical and surgical treatments. Allergy. 2005;60(4):452-458. 
18. Mygind N, Dahl R, Bachert C. Nasal polyposis, eosinophil dominated inflammation, and allergy. Thorax. 2000;55(Suppl 2):S79-S83.

19. Ray NF, Baraniuk JN, Thamer M, et al. Direct expenditures for the treatment of allergic rhinoconjunctivitis in 1996, including the contributions of related airway illnesses. J Allergy Clin Immunol. 1999; 103(3 Pt 1):401-407.

20. Cherry DK, Hing E, Woodwell DA, Rechtsteiner EA. National Ambulatory Medical Care Survey: 2006 summary. Natl Health Stat Report. 2008 Aug 6; (3):1-39.

21. Cherry DK, Woodwell DA, Rechtsteiner EA. National Ambulatory Medical Care Survey: 2005 summary. Adv Data. 2007;(387):1-39.

22. American Academy of Allergy, Asthma, and Immunology, Inc. The Allergy Report. Available from: http://www.aaaai.org/ar. Accessed August 6, 2009.

23. Malone DC, Lawson KA, Smith DH, Arrighi HM, Battista C. A cost of illness study of allergic rhinitis in the United States. J Allergy Clin Immunol. 1997;99(1 Pt 1):22-27.

24. Centers for Disease Control and Prevention (CDC). Self-reported asthma prevalence among adults - United States, 2000. MMWR Morb Mortal Wkly Rep. 2001;50(32):682-686.

25. Prenner BM, Schenkel E. Allergic rhinitis: treatment based on patient profiles. Am J Med. 2006;119(3):230-237.

26. Bousquet J, Bullinger M, Fayol C, Marquis P, Valentin B, Burtin B. Assessment of quality of life in patients with perennial allergic rhinitis with the French version of the SF-36 Health Status Questionnaire. J Allergy Clin Immunol. 1994;94(2 Pt 1):182-188.
27. Meltzer EO. The prevalence and medical and economic impact of allergic rhinitis in the United States. J Allergy Clin Immunol. 1997; 99(6 Pt 2):S805-S828.

28. Tripathi A, Patterson R. Impact of allergic rhinitis treatment on quality of life. Pharmacoeconomics. 2001;19(9):891-899.

29. Kaliner MA, Osguthorpe JD, Fireman P, et al. Sinusitis: bench to bedside. Current findings, future directions. Otolaryngol Head Neck Surg. 1997;116(6 Pt 2):S1-S20.

30. Goetzel RZ, Hawkins K, Ozminkowski RJ, Wang S. The health and productivity cost burden of the "top 10" physical and mental health conditions affecting six large US employers in 1999. J Occup Environ Med. 2003;45(1):5-14.

31. Fokkens W, Lund V, Bachert C, et al. EAACI position paper on rhinosinusitis and nasal polyps executive summary. Allergy. 2005;60(5):583-601.

32. Shedden A. Impact of nasal congestion on quality of life and work productivity in allergic rhinitis: findings from a large online survey. Treat Respir Med. 2005;4(6):439-446.

33. Roper Public Affairs Group of NOP World. Impact of nasal congestion among allergic rhinitis sufferers. May-June 2004. Data on file, Schering Corporation, Kenilworth, NJ.

34. Gurevich F, Glass C, Davies M, et al. The effect of intranasal steroid budesonide on the congestion-related sleep disturbance and daytime somnolence in patients with perennial allergic rhinitis. Allergy Asthma Proc. 2005;26(4):268-274.

35. Forbes Consulting Group. Understanding the dynamics surrounding allergy suffering and treatment. September 2005. Data on file, Schering Corporation, Kenilworth, NJ.
International Journal of General Medicine

\section{Publish your work in this journal}

The International Journal of General Medicine is an international, peer-reviewed open-access journal that focuses on general and internal medicine, pathogenesis, epidemiology, diagnosis, monitoring and treatment protocols. The journal is characterized by the rapid reporting of reviews, original research and clinical studies across all disease areas.

\section{Dovepress}

A key focus is the elucidation of disease processes and management protocols resulting in improved outcomes for the patient.The manuscript management system is completely online and includes a very quick and fair peer-review system. Visit http://www.dovepress.com/ testimonials.php to read real quotes from published authors. 